\title{
Depressive symptoms and other risk factors predicting suicide in middle-aged men: A prospective cohort study among Korean Vietnam War veterans
}

Sang-Wook Yi, Jae-Seok Hong

Background. Few studies have prospectively examined whether depressive symptoms and other risk factors are associated with a higher risk of increase suicide death in individuals other than high-risk populations, such as psychiatric patients and individuals with self-harm histories. The purpose of the study is to prospectively examine whether depressive symptoms assessed by the Beck Depression Inventory (BDI) are associated with greater risk of suicide death and whether depressive symptoms and other risk factors are independent predictors of suicide in general-risk populations. Another aim is to evaluate the sensitivity of the BDI for predicting suicide death. Methods. 10,238 Korean Vietnam War veterans (mean age: 56.4 years) who participated in two surveys in 2001 were followed up for suicide mortality over 7.5 years. Results. 41 men died by suicide. Severely depressed participants had a higher adjusted hazard ratio (aHR $=3.4 ; 95 \%$ $\mathrm{Cl}=1.5-7.7)$ of suicide than non-to-moderately depressed ones. Higher suicide risk was associated with more severe depressive symptoms ( $p$ for trend=0.009). After adjustment for depressive symptoms and other factors, very poor health, low education, and past drinking were associated with higher suicide risk, while good health, body mass index, and marital status were not associated with suicide. The sensitivity at the cut-off score of 31 for detecting suicide was higher during the earlier 3.5 years of the follow-up (75\%; $95 \%$ $\mathrm{Cl}=50-90)$ than during the latter 4 years (60\%; $95 \% \mathrm{Cl}=41-76)$. Conclusions. Depressive symptoms are a strong independent predictor and very poor health, low education, and drinking status may be independent predictors of future suicide. The BDI may have acceptable diagnostic properties as a risk assessment tool for identifying people with depression and suicidal potential among middle-aged men. 
2 Depressive symptoms and other risk factors predicting suicide in

3 middle-aged men: A prospective cohort study among Korean Vietnam

4 War veterans

5

6 Running Head: Depressive symptoms and suicide death

8 Sang-Wook $\mathrm{Yi}^{1,2 *}$, Jae-Seok Hong ${ }^{3}$

Yi SW, Hong JS (Surname initial-of-given name)

${ }^{1}$ Department of Preventive Medicine and Public Health, Catholic Kwandong University College of Medicine, Gangneung, Republic of Korea

${ }^{2}$ Institute for Clinical and Translational Research, Catholic Kwandong University, Gangneung,

Republic of Korea

${ }^{3}$ Department of Healthcare Management, Cheongju University College of Health Science,

Cheongju, Republic of Korea

Correspondence: SW Yi, Department of Preventive Medicine and Public Health, Catholic

Kwandong University College of Medicine, Bumil-ro 579-beongil 24, Gangneung, Gangwon-do, 
24 Abbreviations

25 AUC, area under the receiver operating characteristics curve; BDI, Beck Depression Inventory;

BMI, body mass index; CI, confidence interval; HR, hazard ratio; KRW, Korean Won; ROC, the

27 receiver operating characteristics;

28

29 


\section{Abstract}

\section{Background.}

Few studies have prospectively examined whether depressive symptoms and other risk factors are associated with a higher risk of suicide death in individuals other than high-risk populations, such as psychiatric patients and individuals with self-harm histories. The purpose of the study is to prospectively examine whether depressive symptoms assessed by the Beck Depression Inventory (BDI) are associated with greater risk of suicide death and whether depressive symptoms and other risk factors are independent predictors of suicide in general-risk populations. Another aim is to evaluate the sensitivity of the BDI for predicting suicide death.

Methods.

10,238 Korean Vietnam War veterans (mean age: 56.4 years) who participated in two surveys in 2001 were followed up for suicide mortality over 7.5 years.

\section{Results.}

41 men died by suicide. Severely depressed participants had a higher adjusted hazard ratio $(\mathrm{aHR}=3.4 ; 95 \% \mathrm{CI}=1.5-7.7)$ of suicide than non-to-moderately depressed ones. Higher suicide risk was associated with more severe depressive symptoms ( $\mathrm{p}$ for trend=0.009). After adjustment for depressive symptoms and other factors, very poor health, low education, and past drinking were associated with higher suicide risk, while good health, body mass index, and marital status were not associated with suicide. The sensitivity at the cut-off score of 31 for detecting suicide was higher during the earlier 3.5 years of the follow-up $(75 \% ; 95 \% \mathrm{CI}=50-90)$ than during the latter 4 years $(60 \% ; 95 \% \mathrm{CI}=41-76)$.

\section{Conclusions.}


52 Depressive symptoms are a strong independent predictor and very poor health, low education,

53 and drinking status may be independent predictors of future suicide. The BDI may have

54 acceptable diagnostic properties as a risk assessment tool for identifying people with depression

55 and suicidal potential among middle-aged men.

56

57 Keywords:

58 Asia; Beck Depression Inventory; cohort studies; depressive symptoms; men; suicide

59 


\section{Introduction}

Over 800,000 people die by suicide worldwide every year (World Health Organization 2014). Suicide prevention is a high priority in many countries. Understanding the risk factors leading to suicide is crucial for effectively preventing suicide and managing individuals at risk of suicide. Depression has been strongly associated with suicide in retrospective psychological autopsy studies (Hawton \& van Heeringen 2009; Yoshimasu et al. 2008), although an over/underestimation of the association, and biases such as interviewer bias, surrogate interview bias, and recall bias may not be ruled out (Hjelmeland et al. 2012). Prospective studies have been conducted mainly among patients with psychiatric disorders, who may not represent the people with psychiatric disorders in the community (Agerbo 2007). Meanwhile, physical health indicators such as health status (Jee et al. 2011) and body mass index (BMI) (Jee et al. 2011; Mukamal et al. 2010), marital status (Masocco et al. 2010), drinking status (Akechi et al. 2006), and socioeconomic status (Milner et al. 2014) have also been linked with suicide. Despite many studies supporting these associations, it has seldom been evaluated and is unclear whether each of those factors were independently associated with suicide after adjusting for the others and, notably, for depression, one of the most important known precursors of suicide (Milner et al. 2014; Mukamal et al. 2010).

Meanwhile, suicide risk assessment using depression tools could be relatively easily embedded in the various health care settings to help primary physicians and public health professionals identify people with depression and suicidal potential. However, to the best of our knowledge, the diagnostic characteristics of depression instruments that can be used for suicide risk assessment have never been evaluated in general-risk populations for predicting suicide death. 

depressive symptoms assessed by the Korean translation of the Beck Depression Inventory (BDI) would be associated with a greater risk of suicide in middle-aged Korean men, specifically

Korean veterans of the Vietnam War. The secondary aim was to evaluate the diagnostic properties of the BDI for predicting suicide death, such as sensitivity, specificity, and area under

the receiver operating characteristics (ROC) curve (AUC). The tertiary aim was to examine whether risk factors such as self-rated health status, drinking, BMI, marital status, and socioeconomic status were independently associated with suicide after adjusting for each other and for depressive symptoms. Korean Vietnam War veterans have had the same suicide mortality (crude mortality, 35.4 deaths per 100,000 person-years during 1992-2005; standardized mortality ratio $=0.95,95 \% \mathrm{CI}=0.89-1.02$ ) expected from the general Korean population in previous research (Yi \& Ohrr 2011).

\section{Methods}

\section{Study participants}

We identified 187,897 Vietnam War veterans during 1999-2000 with the cooperation of the Ministry of Defense and then the Ministry of Government Administration and Home Affairs (Yi et al. 2014). Among them, 20,000 veterans were selected by a simple random sample. After excluding 1737 individuals who were deceased, had emigrated to another country, or had an unknown residency status as of July 2000, 18,263 were recruited for a health exam or survey. Among them, randomly selected 5000 veterans (health exam group) were invited to a health exam and a survey by mail on May 4, 2001, and the other 13,263 (survey-only group) received a survey sent out on July 20, 2001. In the end, 10,238 veterans who participated in the health exam 
106

107

108

109

110 111 0105).

112

\section{3}

114

115

or survey (health exam group, $n=2005$; survey-only group, $n=8233$ ) were followed up on suicide mortality until December 31, 2008 (Figure S1). The veterans were provided with a written summary about the research and an invitation to the health exam by post. Return of the postal survey and voluntary participation of health exam were considered implied consent. This study was approved by the Institutional Review Board of Kwandong University (Approval No: KD-13-

\section{Follow-up and ascertainment of suicide death}

The deaths from suicide were ascertained from the 2001-2008 death records of the National Statistical Office. When veterans had emigrated to another country or their residential status was unknown between enrollment and December 2008, the changed date of the residential status was considered the date of a loss to follow-up. A complete follow-up was made for 10,181 veterans (99.4\%). Suicide was identified by the International Classification of Diseases, 10th Revision codes X60-X84.

\section{Measures of depressive symptoms}

The self-administered BDI, with 21 items each measured on a 4-point Likert scale (0-3) and a total score range of 0-63, was used to assess depressive symptoms.(Beck et al. 1961) The previous Korean-language version of the BDI, translated by two psychiatrists and a clinical psychologist,(Rhee et al. 1995) was modified for the present study by two medical doctors, and several graduate students of public health. The internal consistency assessed by Cronbach's alpha was 0.937 in a complete data analysis.

The participants were categorized into two groups (no-to-moderate [0-30] and severe [31- 
129

130

131

132

133

134

135

136

63]) and five groups (depressive symptoms [BDI score]: none [0-13], mild [14-21], moderate [22-30], severe [31-39], and extreme [40-63]) based on quartiles and the highest decile of BDI score. For a sensitivity analysis, they were also categorized based on cut-off score in previous research into two groups (no-to-moderate [0-29] and severe [30-63]) and five groups (none [0-9], mild [10-16], moderate [17-29], severe [30-40], and extreme [41-63]) (Al-Turkait \& Ohaeri 2010; Beck \& Steer 1987; Smarr \& Keefer 2011).

\section{Measures of other risk factors}

Self-rated health, smoking, drinking (“Do you drink alcohol?” [Yes, No. I quit drinking, or Never]), marital status, educational status, and household monthly income were collected through self-reported survey. Self-rated health was assessed by a 5-point Likert scale. Weight and height were measured among participants in health exams, while they were self-reported among the survey-only group. The BMI was obtained from weight divided by the height squared $\left(\mathrm{kg} / \mathrm{m}^{2}\right)$.

\section{Statistical Analysis}

Among the 10,238 participants, $3156(30.8 \%)$ had one or more missing baseline data including smoking $(n=55)$, drinking $(n=84)$, BMI $(n=102)$, self-rated health $(n=186)$, marital status ( $n=143)$, educational status $(n=195)$, income status $(n=426)$, or at least one item on the BDI ( $\mathrm{n}=2761)$. Multiple imputation was performed to estimate the missing baseline data with SAS PROC MI. Markov chain Monte Carlo sampling methods and an expectation-maximization algorithm with a separate chain for each imputation (chain=multiple) were used. 100 imputations were made using all variables analyzed in this study and other variables including military 
152 variables (such as Agent Orange exposure index, unit served and military rank during Vietnam

153 service), and self-rated health compared to the same age group. Imputation methods including

154 number of imputations were selected to minimize imputation variance and to ensure the

155 confidence intervals and $p$ values to be reliable (White et al. 2011). 
The test for trend was done to demonstrate the dose-response relationships of the risk factors (every variable with three or more categories) to suicide by analyzing categories of a risk factor as ordinal variables. Additionally, analyses in all of the participants with follow-up until 2004, and analyses in survivors as of January 1, 2005 with follow-up until 2008, were done to evaluate whether the association of depressive symptoms and other risk factors with suicide, and the diagnostic characteristics of the BDI differ by follow-up period, and these calculations served as sensitivity (robustness) analyses. To test the non-response bias and potential harm of the screening for suicide, the suicide mortality and age-adjusted hazard ratio (HR) of suicide of the participants $(n=10,238)$ were compared with those of the non-participants $(n=7867)$.

All statistical analyses were performed using SAS version 9.4 (SAS Inc., Cary, NC, USA). The p-value was calculated with two-sided tests. The proportional hazard assumption was tested using Martingale residuals and Schoenfeld residuals in complete data and imputed data analyses. No variables had evidence of a violation of the proportional hazard assumption except for a dummy variable of self-reported health (very good or good, only one suicide) in the complete data analysis.

\section{Results}

\section{Characteristics of participants}

The total follow-up person-years was 73,916. 41 men died by suicide (5.5 per 10,000 person-years, 95\% $\mathrm{CI}=4.1-7.5)$ during around 7.5 years of follow-up. The average (SD) age of the Korean veterans was 56.4 (3.7) years at enrollment. Participants with severe depressive symptoms were slightly younger than those with no-to-moderate symptoms, and they tended to be current smokers, past drinkers, slim, living without a spouse, unhealthy, and have little formal 
198

199

education and low earnings, compared to those with no-to-moderate symptoms (Table 1).

\section{Associations of depressive symptoms and other risk factors with suicide}

In the unadjusted analysis, participants with severely depressive symptoms had a higher HR of suicide than those with no-to-moderately depressive symptoms, and increasing HR of suicide was associated with increasing depressive symptoms across the five categories of intensity (p for trend <.001) (Table 2, Table S1). Additionally, higher suicide risk correlated with a higher BDI score. After adjustment for various risk factors for suicide, the association of depressive symptoms with suicide (although somewhat weaker than before) remained strong. Unadjusted HRs indicated that very poor health $(\mathrm{p}<0.001)$, low education $(\mathrm{p}=0.002)$, low household income $(\mathrm{p}=0.03)$, past drinking $(\mathrm{p}=0.07)$ and living without a spouse $(\mathrm{p}=0.09)$ were associated with a higher risk of suicide, while obesity (BMI $\geq 25)$ with a lower risk of suicide $(\mathrm{p}=0.07)$ (Table 3$)$. In the unadjusted trend test across categories of risk factors, poorer self-rated health, lower education, and lower income were associated with a higher risk of suicide, while more obese subjects were less likely to die by suicide. After adjustment for depressive symptoms and other risk factors, very poor health, low education, and past drinking were still related to a higher HR of suicide, while BMI and marital status were not associated with suicide (Table 3, Table S6). In the adjusted trend test across categories of risk factors, only educational status remained statistically significantly associated with suicide $(\mathrm{p}=0.03)$.

The associations of depressive symptoms with suicide were generally stronger during the earlier period of follow-up than during the later period (Table 4, Table S2). The associations of most of the other risk factors with suicide were also generally stronger (although none of them had a p-value below 0.05 due to the small number of suicide deaths) during the earlier period 
221 than the later period, while educational status was more strongly associated with suicide during

222 the later period than the earlier period (Table S3).

\section{Diagnostic properties of the Beck Depression Inventory}

For the unbinned total score and cut-off score of 31 or above, respectively, the AUC

226

227

228

values were 0.71 and 0.69 during the follow-up, and they were higher during the first half of follow-up (2001-2004) than during the latter half (2005-2008) (Table 5, Figure S2, Table S4).

The overall sensitivity and specificity of the 2-group test at a cut-off score of 31 or above on predicting suicide during 7.5 years of follow-up were $66 \%(95 \% \mathrm{CI}=50-78)$ and $73 \%(95 \%$ $\mathrm{CI}=72-74$ ), respectively. The sensitivity decreased over the follow-up period, while the specificity remained relatively unchanged. The AUC analyses showed that cut-off score of 31 or above had the highest AUC values across cut-off scores of BDI for predicting suicide (Table S5).

\section{Discussion}

\section{Depressive symptoms and suicide}

Severe depressive symptoms were more strongly associated with suicide compared to noto-moderate depressive symptoms in this study, after adjusting for other potential risk factors for suicide, although the association was weaker than that of depressive disorders examined in psychological autopsy studies (Yoshimasu et al. 2008). The association of depressive symptoms with suicide was stronger during the first 3.5 years of follow-up than during the latter 4-year period in accordance with previous research (Bramness et al. 2010; Sun et al. 2012). This indicates that a cohort study of long follow-up with one baseline assessment and without considering the change in depressive symptoms during the follow-up, may underestimate the 
effects of depressive symptoms on suicide (Bramness et al. 2010). Additionally, in the current study, higher suicide risk was associated with a higher depressive symptom score in accordance with previous cohort studies in general-risk populations (Bramness et al. 2010; Sun et al. 2012). Overall, this prospective cohort study confirmed that depressive symptoms were a strong predictor of future suicide.

\section{Diagnostic characteristics of Beck Depression Inventory}

To the best of our knowledge, this is the first study that has reported diagnostic characteristics for suicide death in a general-risk population. Although studies on suicidal ideation or attempt have been performed, attempters may share some properties with suicides; however, they may be two different populations, especially among males (Isometsa \& Lonnqvist 1998; Parra Uribe et al. 2013). The sensitivity and specificity at the cut-off score of 31 or above of the BDI in Korean middle-aged men for predicting future suicide, especially during the earlier period of follow-up, was comparable at least to those of other tools such as the Beck Hopelessness Scale (sensitivity $80 \%$, specificity $42 \%$ ) (McMillan et al. 2007), Beck Suicide Intent Scale (sensitivity 77\%, specificity 49\%) (Harriss \& Hawton 2005), and a tool constructed from stepwise discriminant analysis of various instruments (sensitivity $56 \%$, specificity 74\%)(Pokorny 1983) that were mainly applied to inpatients with psychiatric disorders or those who had done self-harm. They are also comparable to those of BDI at cut-off score of 23 or above in psychiatric outpatients (sensitivity $76 \%$, specificity 62\%) (Beck et al. 1990) and those of BDI-II at cut-off score of 31 or above in prisoners (for attempted suicide or self-harm incident; sensitivity $80 \%$, specificity $69 \%$ ) (Perry \& Gilbody 2009). Although there is a room for improvement, the BDI may have an acceptable sensitivity and specificity as a suicide risk 
assessment tool.

It has been reported that male patients rarely initiated suicide-related discussions with their physician (Vannoy \& Robins 2011), while physicians were also reluctant to discuss suicide for various reasons including the fear of stimulating suicide in patients with depression by asking about it (Crawford et al. 2011; Schulberg et al. 2004). The suicide mortality of the participants in the present study (41 suicides, 5.5 suicides per 10,000 person-years) was not higher than that of the non-participants (34 suicides in 7867 men, 6.0 [95\% CI=4.3-8.4] suicides per 10,000 personyears $)$, and the age-adjusted hazard ratio of suicide $(0.93,95 \% \mathrm{CI}=0.59-1.46)$ also was not higher in the participants compared to non-participants. These results suggest that asking people about depressive symptoms using the BDI does not seem to be associated with a higher risk of suicide.

\section{Other risk factors and suicide}

Although physical health, marital status, drinking, and socioeconomic status have been associated with suicide in previous research, their association with suicide has rarely been examined after adjustment for depression (Conwell et al. 2002), especially in a prospective manner. Marital status was not associated with suicide in clinical patients with depression in a systematic review (Hawton et al. 2013), and it was also not associated with suicide after adjusting for other risk factors in a large psychological autopsy study in China (Phillips et al. 2002). Although BMI was inversely associated with suicide in large cohort studies, depressive symptoms were not accounted for in those studies (Jee et al. 2011; Mukamal et al. 2010). A review also concluded that much, if not all, of the association of physical health factors with suicide was mediated by affective disorders (Conwell et al. 2002).

In prospective studies, evidence linking regular alcohol consumption with suicide death is 
lacking (Jee et al. 2011; Mukamal et al. 2007), except for serious alcohol-related conditions such as alcohol use disorder and very heavy drinking (Akechi et al. 2006; LeardMann et al. 2013). Meanwhile, higher risks of suicide in past drinkers have also been identified in Japanese middleaged men (depression was not adjusted for, though, in the Japanese study) (Akechi et al. 2006). As for socioeconomic status, despite a strong dose-response relationship of both educational status and household income with suicide in unadjusted analysis, the association of household income was substantially weakened after adjustment for self-rated health and depressive symptoms, because household income status was strongly associated with self-rated health and depressive symptoms in the current study.

Our findings suggest that very poor health, low education, and drinking status may be independently associated with suicide, while good or fair health, BMI, household income, and marital status may not be factors independently related factors to suicide. Instead, the associations of these non-independent factors with suicide may rather be mediated through depressive symptoms and other factors in Korean middle-aged men.

\section{Limitations of the study}

Despite of the strengths of the study, such as nearly complete prospective follow-up on suicide using national mortality data and the analysis of the diagnostic characteristics of a potential suicide risk assessment tool on suicide death in a general-risk population, this study has some limitations. First, our findings are based on 41 suicides, so the study may have lacked statistical power in some analyses. In particular, risk factors having a weak association with suicide may not be clearly identified in this study. Second, in cohort studies, nonresponse to the baseline survey may introduce bias. However, the suicide mortality of 7867 (43\%) non- 
respondents did not differ from that of participants, and item non-response to questionnaires was

314 minimized with multiple imputation of 100 datasets. Third, the validity of the suicide death listed

315

on death certificates was not examined separately. Since any misclassification on the suicide

death could be most likely non-differential according to depressive symptoms, potential

misclassifications would not substantially overestimate the hazard ratios.

It may be a limitation of its generalizability that this study's participants were Korean

Vietnam War veterans. However, among US military personnel, mental health problems but not military-specific variables were independent risk factors for suicide (LeardMann et al. 2013).

Additionally, the suicide mortality in Korean Vietnam War veterans did not differ from that from the male population of Korea (Yi \& Ohrr 2011). Therefore, we believe that performing the study with Vietnam War veterans did not substantially hinder its generalizability. Meanwhile, although psychological disorders such as depression have been universal risk factors among many cultural groups (Sun et al. 2012; Zhang et al. 2004), the strength of association and the association in itself of some risk factors with suicide may differ by ethnicity, culture, age, and gender (Bjerkeset et al. 2008; Goldston et al. 2008; Milner et al. 2013; Sun et al. 2012; Zhang et al. 2004). Therefore, some results in Korean middle-aged men may not be generalizable to other ethnic, cultural, or age groups, or to females.

\section{Conclusions}

Although the association was weaker than estimated from psychological autopsy studies, this study prospectively confirmed that depressive symptoms are a strong independent predictor of suicide. The sensitivity and specificity at the BDI cut-off score of 31 or above in Korean middle-aged men for predicting future suicide during 2001-2008 were $66 \%(95 \% \mathrm{CI}=50-78)$ and 
$33673 \%(95 \% \mathrm{CI}=72-74)$, respectively. They were $75 \%(95 \% \mathrm{CI}=50-90)$ and $73 \%(95 \% \mathrm{CI}=72-74)$,

337 respectively, for predicting future suicide during 2001-2004. BDI may have an acceptable

338 sensitivity and specificity as a suicide risk assessment tool to help physicians and public health

339 professionals identify individuals with depression and suicidal potential. This study also suggests

340 that very poor self-rated health, drinking status and low education, but not marital status and

341 BMI, may be independent predictors of suicide.

342 
343 Acknowledgement

344 The authors truly thank the staff of the National Statistical Office of Korea for providing the 345 national mortality data.

346

347 Conflict of interest statement: None.

348

349

350 
References

Agerbo E. 2007. High income, employment, postgraduate education, and marriage: a suicidal cocktail among psychiatric patients. Archives of General Psychiatry 64:1377-1384.

Akechi T, Iwasaki M, Uchitomi Y, and Tsugane S. 2006. Alcohol consumption and suicide among middle-aged men in Japan. British Journal of Psychiatry 188:231-236.

Al-Turkait FA, and Ohaeri JU. 2010. Dimensional and hierarchical models of depression using the Beck Depression Inventory-II in an Arab college student sample. BMC Psychiatry 10:60.

Beck AT, Brown G, Berchick RJ, Stewart BL, and Steer RA. 1990. Relationship between hopelessness and ultimate suicide: a replication with psychiatric outpatients. American Journal of Psychiatry 147:190-195.

Beck AT, and Steer RA. 1987. Manual for the Beck Depression Inventory. San Antonio, TX: Psychological Corporation.

Beck AT, Ward CH, Mendelson M, Mock J, and Erbaugh J. 1961. An inventory for measuring depression. Archives of General Psychiatry 4:561-571.

Bjerkeset O, Romundstad P, and Gunnell D. 2008. Gender differences in the association of mixed anxiety and depression with suicide. British Journal of Psychiatry 192:474-475.

Bramness JG, Walby FA, Hjellvik V, Selmer R, and Tverdal A. 2010. Self-reported mental health and its gender differences as a predictor of suicide in the middle-aged. American Journal of Epidemiology 172:160-166.

Conwell Y, Duberstein PR, and Caine ED. 2002. Risk factors for suicide in later life. Biological Psychiatry 52:193-204.

Crawford MJ, Thana L, Methuen C, Ghosh P, Stanley SV, Ross J, Gordon F, Blair G, and Bajaj 
P. 2011. Impact of screening for risk of suicide: randomised controlled trial. British Journal of Psychiatry 198:379-384.

Goldston DB, Molock SD, Whitbeck LB, Murakami JL, Zayas LH, and Hall GC. 2008. Cultural considerations in adolescent suicide prevention and psychosocial treatment. American Psychologist 63:14-31.

Harriss L, and Hawton K. 2005. Suicidal intent in deliberate self-harm and the risk of suicide: the predictive power of the Suicide Intent Scale. Journal of Affective Disorders 86:225233.

Hawton K, Casanas ICC, Haw C, and Saunders K. 2013. Risk factors for suicide in individuals with depression: a systematic review. Journal of Affective Disorders 147:17-28.

Hawton K, and van Heeringen K. 2009. Suicide. Lancet 373:1372-1381.

Hjelmeland H, Dieserud G, Dyregrov K, Knizek BL, and Leenaars AA. 2012. Psychological autopsy studies as diagnostic tools: are they methodologically flawed? Death Studies 36:605-626.

Isometsa ET, and Lonnqvist JK. 1998. Suicide attempts preceding completed suicide. British Journal of Psychiatry 173:531-535.

Jee SH, Kivimaki M, Kang HC, Park IS, Samet JM, and Batty GD. 2011. Cardiovascular disease risk factors in relation to suicide mortality in Asia: prospective cohort study of over one million Korean men and women. European Heart Journal 32:2773-2780.

LeardMann CA, Powell TM, Smith TC, Bell MR, Smith B, Boyko EJ, Hooper TI, Gackstetter GD, Ghamsary M, and Hoge CW. 2013. Risk factors associated with suicide in current and former US military personnel. JAMA 310:496-506.

Masocco M, Pompili M, Vanacore N, Innamorati M, Lester D, Girardi P, Tatarelli R, and Vichi 
M. 2010. Completed suicide and marital status according to the Italian region of origin. Psychiatric Quarterly 81:57-71.

McMillan D, Gilbody S, Beresford E, and Neilly L. 2007. Can we predict suicide and non-fatal self-harm with the Beck Hopelessness Scale? A meta-analysis. Psychological Medicine 37:769-778.

Milner A, Hjelmeland H, Arensman E, and De Leo D. 2013. Social-environmental factors and suicide mortality. Sociology Mind 3:137-148.

Milner A, Page A, and Lamontagne AD. 2014. Cause and effect in studies on unemployment, mental health and suicide: a meta-analytic and conceptual review. Psychological Medicine 44:909-917.

Mukamal KJ, Kawachi I, Miller M, and Rimm EB. 2007. Drinking frequency and quantity and risk of suicide among men. Social Psychiatry and Psychiatric Epidemiology 42:153-160.

Mukamal KJ, Rimm EB, Kawachi I, O'Reilly EJ, Calle EE, and Miller M. 2010. Body mass index and risk of suicide among one million US adults. Epidemiology 21:82-86.

Newcombe RG. 1998. Interval estimation for the difference between independent proportions: comparison of eleven methods. Statistics in Medicine 17:873-890.

Parra Uribe I, Blasco-Fontecilla H, Garcia-Pares G, Giro Batalla M, Llorens Capdevila M, Cebria Meca A, de Leon-Martinez V, Perez-Sola V, and Palao Vidal DJ. 2013. Attempted and completed suicide: not what we expected? Journal of Affective Disorders 150:840-846.

Perry AE, and Gilbody S. 2009. Detecting and predicting self-harm behaviour in prisoners: a prospective psychometric analysis of three instruments. Social Psychiatry and Psychiatric Epidemiology 44:853-861. 
Phillips MR, Yang G, Zhang Y, Wang L, Ji H, and Zhou M. 2002. Risk factors for suicide in China: a national case-control psychological autopsy study. Lancet 360:1728-1736.

Pokorny AD. 1983. Prediction of suicide in psychiatric patients. Report of a prospective study. Archives of General Psychiatry 40:249-257.

Rhee M, Lee Y, Park S, Sohn C, Chung Y, Hong S, Lee B, Chang P, and Yoon A. 1995. A standardization study of Beck Depression Inventory I-Korean version (K-BDI): reliability and factor analysis. Korean Journal of Psychopathology 4:77-95.

Schulberg HC, Bruce ML, Lee PW, Williams JW, Jr., and Dietrich AJ. 2004. Preventing suicide in primary care patients: the primary care physician's role. General Hospital Psychiatry $26: 337-345$.

Smarr KL, and Keefer AL. 2011. Measures of depression and depressive symptoms: Beck Depression Inventory-II (BDI-II), Center for Epidemiologic Studies Depression Scale (CES-D), Geriatric Depression Scale (GDS), Hospital Anxiety and Depression Scale (HADS), and Patient Health Questionnaire-9 (PHQ-9). Arthritis Care \& Research 63 Suppl 11:S454-466.

Sun WJ, Xu L, Chan WM, Lam TH, and Schooling CM. 2012. Depressive symptoms and suicide in 56,000 older Chinese: a Hong Kong cohort study. Social Psychiatry and Psychiatric Epidemiology 47:505-514.

Vannoy SD, and Robins LS. 2011. Suicide-related discussions with depressed primary care patients in the USA: gender and quality gaps. A mixed methods analysis. BMJ Open $1: \mathrm{e} 000198$.

White IR, Royston P, and Wood AM. 2011. Multiple imputation using chained equations: Issues and guidance for practice. Statistics in Medicine 30:377-399. 
443 World Health Organization. 2014. Preventing suicide: a global imperative. Geneva: World $444 \quad$ Health Organization.

445 Yi SW, and Ohrr HC. 2011. Mortality Patterns among Korean Vietnam Veterans. Korean 446 Journal of Occupational and Environmental Medicine 23:279-286.

447 Yi SW, Ryu SY, Ohrr H, and Hong JS. 2014. Agent Orange exposure and risk of death in 448 Korean Vietnam veterans: Korean Veterans Health Study. International Journal of $449 \quad$ Epidemiology:In press.

450 Yoshimasu K, Kiyohara C, Miyashita K, and Stress Research Group of the Japanese Society for Hygiene. 2008. Suicidal risk factors and completed suicide: meta-analyses based on psychological autopsy studies. Environmental Health and Preventive Medicine 13:243256.

454 Zhang J, Conwell Y, Zhou L, and Jiang C. 2004. Culture, risk factors and suicide in rural China: a psychological autopsy case control study. Acta Psychiatrica Scandinavica 110:430-437. 


\section{Table $\mathbf{1}$ (on next page)}

Characteristics of the Korean middle-aged male participants by depressive symptoms

BDI, Beck Depression Inventory; BMI, body mass index; SD, standard deviation. a. Combined $p$-value of chi-squared analysis over multiple imputed data. b. Combined $p$-value of analysis of variance over multiple imputed data. c. Sum of the number of participants from both groups may not equal the total due to rounding of averages over multiple imputed data. $d$. 1300 Korean Won was about one US dollar as of June, 2001 e. Cut-off score based on quartiles and the last decile. f. Cut-off score based on previous research. 


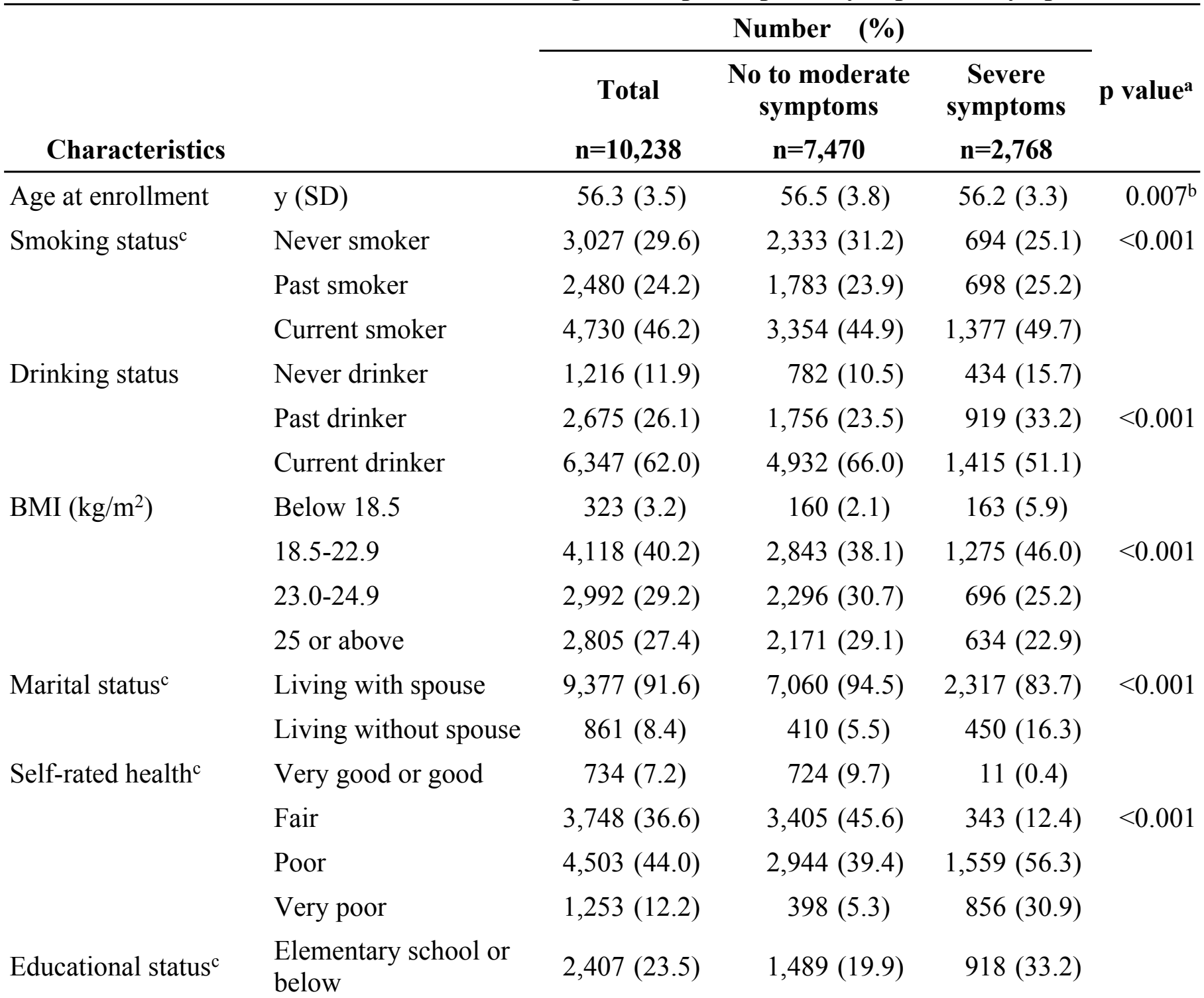




\begin{tabular}{|c|c|c|c|c|c|}
\hline \multirow[b]{3}{*}{ Characteristics } & & \multicolumn{3}{|c|}{ Number $(\%)$} & \multirow{3}{*}{ p value ${ }^{a}$} \\
\hline & & \multirow{2}{*}{$\begin{array}{c}\text { Total } \\
\mathbf{n}=\mathbf{1 0 , 2 3 8}\end{array}$} & \multirow{2}{*}{$\begin{array}{l}\text { No to moderate } \\
\text { symptoms } \\
n=7,470\end{array}$} & \multirow{2}{*}{$\begin{array}{c}\text { Severe } \\
\text { symptoms } \\
\mathbf{n = 2 , 7 6 8}\end{array}$} & \\
\hline & & & & & \\
\hline & Middle school & $2,782(27.2)$ & $1,934(25.9)$ & $848(30.6)$ & $<0.001$ \\
\hline & High school or above & $5,049(49.3)$ & $4,048(54.2)$ & $1,002(36.2)$ & \\
\hline Household income ${ }^{c}$ & Below 1,000,000 & $3,450(33.7)$ & $1,852(24.8)$ & $1,597(57.7)$ & \\
\hline per month & $1,000,000-1,990,000$ & $4,693(45.8)$ & $3,707(49.6)$ & $987(35.6)$ & $<0.001$ \\
\hline$(\text { Korean Won })^{\mathrm{d}}$ & $2,000,000$ or more & $2,095(20.5)$ & $1,911(25.6)$ & $184(6.7)$ & \\
\hline \multirow[t]{2}{*}{ Participant group } & Survey-only group & $8,233(80.4)$ & $5,881(78.7)$ & $2,352(85.0)$ & $<0.001$ \\
\hline & Health exam group & $2,005(19.6)$ & $1,589(21.3)$ & $416(15.0)$ & \\
\hline \multirow{5}{*}{$\begin{array}{l}\text { Depressive symptoms 1) } \\
\text { (BDI score) }\end{array}$} & No $(0-13)$ & $2,360(23.0)$ & $2,360(31.6)$ & $0(0.0)$ & \\
\hline & Mild (14-21) & $2,554(24.9)$ & $2,554(34.2)$ & $0(0.0)$ & \\
\hline & Moderate (22-30) & $2,556(25.0)$ & $2,556(34.2)$ & $0(0.0)$ & $<0.001$ \\
\hline & Severe (31-39) & $1,627(15.9)$ & $0(0.0)$ & $1,627(58.8)$ & \\
\hline & Extreme (40-63) & $1,141(11.1)$ & $0(0.0)$ & $1,141(41.2)$ & \\
\hline \multirow{5}{*}{$\begin{array}{l}\text { Depressive symptoms } 2)^{f} \\
\text { (BDI score) }\end{array}$} & No $(0-9)$ & $1,307(12.8)$ & $1,307(17.5)$ & $0(0.0)$ & \\
\hline & Mild (10-16) & $2,625(25.6)$ & $2,625(35.1)$ & $0(0.0)$ & \\
\hline & Moderate (17-29) & $3,281(32.0)$ & $3,281(43.9)$ & $0(0.0)$ & $<0.001$ \\
\hline & Severe $(30-40)$ & $2,015(19.7)$ & $257(3.4)$ & $1,758(63.5)$ & \\
\hline & Extreme (41-63) & $1,010(9.9)$ & $0(0.0)$ & $1,010(36.5)$ & \\
\hline
\end{tabular}

3 


\section{Table 2 (on next page)}

Hazard ratios of suicides by depressive symptoms in Korean middle-aged men $(n=10,238)^{a}$

a. Hazard ratios were calculated using a Cox proportional hazards model over multiple imputed data. b. Adjusted for age at enrollment, smoking status, drinking status, body mass index, self-rated health, marital status, educational status, household monthly income and participant group. c. Number of suicides may not match those of the other groups of depressive symptoms due to rounding of averages over multiple imputed data. d. Cut-off score based on quartiles and the last decile. e. Five categories of Depressive symptoms were analyzed as ordinal variables. 
Table 2. Hazard ratios of suicides by depressive symptoms in Korean middle-aged men $(\mathrm{n}=10,238)^{\mathrm{a}}$

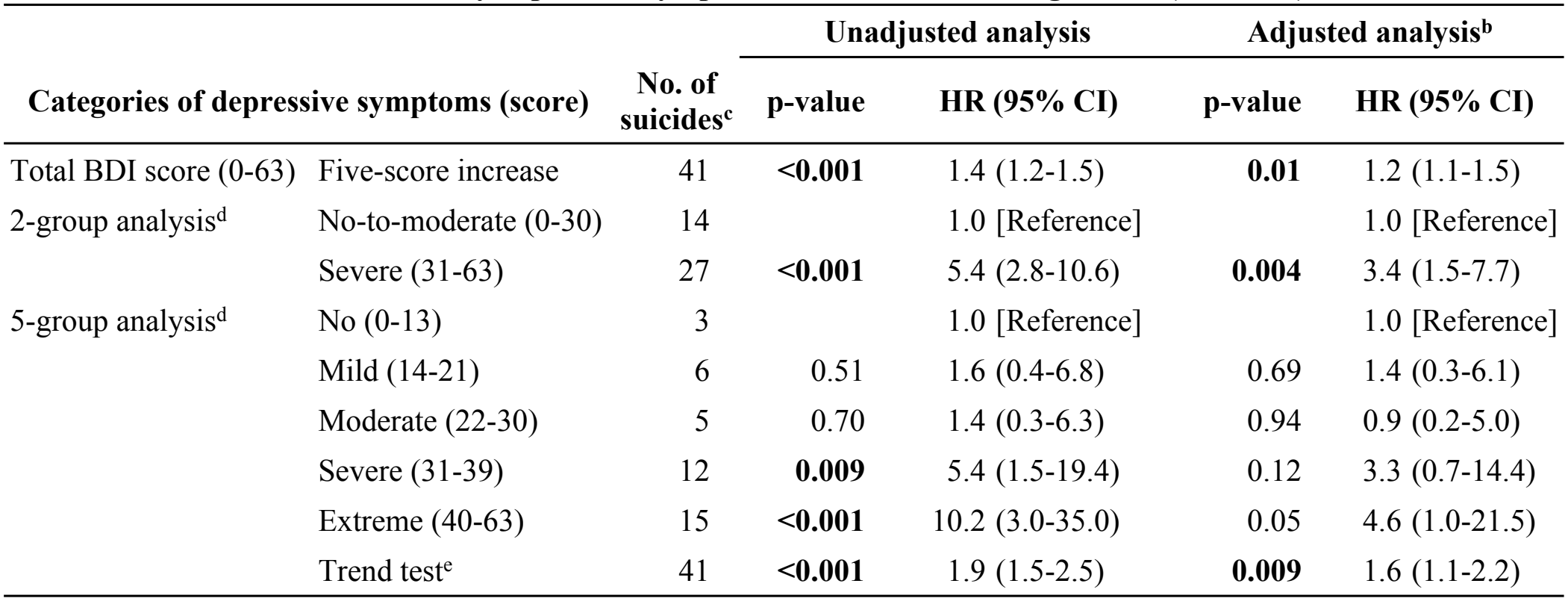




\section{Table 3(on next page)}

Hazard ratios of suicides by risk factors in Korean middle-aged men $(n=10,238)^{a}$

$\mathrm{BDI}$, Beck Depression Inventory; $\mathrm{Cl}$, confidence interval; $\mathrm{HR}$, hazard ratio. a. Hazard ratios were calculated using a Cox proportional hazards model over multiple imputed data. $b$. Variables included in the Cox model were age at enrollment, smoking status, drinking status, body mass index, self-rated health, marital status, educational status, household monthly income, participant group, and depressive symptoms (5 categories based on quartiles and the last decile of the total BDI score). c. Sum of the number of suicides may not equal the total suicides $(n=41)$ due to rounding of averages over multiple imputed data. $d$. Categories of risk factors were analyzed as ordinal variables. e. 1300 Korean Won was about one US dollar as of June, 2001. 


\begin{tabular}{|c|c|c|c|c|c|c|}
\hline \multirow{2}{*}{\multicolumn{2}{|c|}{ Categories of risk factors }} & \multirow{3}{*}{$\begin{array}{r}\begin{array}{c}\text { No. of } \\
\text { suicides }\end{array} \\
41\end{array}$} & \multicolumn{2}{|c|}{ Unadjusted analysis } & \multicolumn{2}{|c|}{ Adjusted analysis $^{b}$} \\
\hline & & & \multirow{2}{*}{$\begin{array}{r}\text { p-value } \\
0.24\end{array}$} & \multirow{2}{*}{$\begin{array}{c}\text { HR }(\mathbf{9 5 \%} \text { CI) } \\
0.9(0.9-1.0)\end{array}$} & \multirow{2}{*}{$\begin{array}{r}\text { p-value } \\
0.27\end{array}$} & \multirow{2}{*}{$\begin{array}{c}\text { HR }(95 \% \text { CI) } \\
0.9(0.8-1.0)\end{array}$} \\
\hline Age at enrollment & One year increase in age & & & & & \\
\hline \multirow[t]{4}{*}{ Smoking status } & Never smoker & 9 & & 1.0 [Reference] & & 1.0 [Reference] \\
\hline & Past smoker & 7 & 0.95 & $1.0(0.4-2.6)$ & 0.51 & $0.7(0.3-2.0)$ \\
\hline & Current smoker & 25 & 0.15 & $1.8(0.8-3.8)$ & 0.47 & $1.3(0.6-2.9)$ \\
\hline & $\mathrm{p}$ for trend $\mathrm{d}^{\mathrm{d}}$ & 41 & 0.11 & $1.4(0.9-2.0)$ & 0.36 & $1.2(0.8-1.8)$ \\
\hline \multirow[t]{4}{*}{ Drinking status } & Never drinker & 1 & & 1.0 [Reference] & & 1.0 [Reference] \\
\hline & Past drinker & 16 & 0.07 & $8.4(0.8-86.9)$ & 0.05 & $8.7(1.0-75.5)$ \\
\hline & Current drinker & 23 & 0.19 & $4.8(0.5-49.1)$ & 0.10 & $6.1(0.7-53.0)$ \\
\hline & $\mathrm{p}$ for trend $\mathrm{d}^{\mathrm{d}}$ & 41 & 0.80 & $1.1(0.7-1.7)$ & 0.29 & $1.3(0.8-2.1)$ \\
\hline Body mass index & Below 18.5 & 2 & 0.79 & $1.2(0.3-5.2)$ & 0.75 & $0.8(0.2-3.4)$ \\
\hline \multirow[t]{4}{*}{$\left(\mathrm{kg} / \mathrm{m}^{2}\right)$} & $18.5-22.9$ & 22 & & 1.0 [Reference] & & 1.0 [Reference] \\
\hline & $23.0-24.9$ & 10 & 0.20 & $0.6(0.3-1.3)$ & 0.55 & $0.8(0.4-1.7)$ \\
\hline & 25 or above & 7 & 0.07 & $0.5(0.2-1.1)$ & 0.23 & $0.6(0.2-1.4)$ \\
\hline & $\mathrm{p}$ for trend $\mathrm{d}^{\mathrm{d}}$ & 41 & 0.04 & $0.7(0.5-1.0)$ & 0.29 & $0.8(0.6-1.2)$ \\
\hline \multirow[t]{5}{*}{ Self-rated health } & Very good or good & 1 & 0.35 & $0.4(0.1-2.9)$ & 0.92 & $1.1(0.1-10.3)$ \\
\hline & Fair & 9 & 0.33 & $0.7(0.3-1.5)$ & 0.71 & $1.2(0.5-2.9)$ \\
\hline & Poor & 16 & & 1.0 [Reference] & & 1.0 [Reference] \\
\hline & Very poor & 15 & $<\mathbf{0 . 0 0 1}$ & $3.6(1.8-7.3)$ & 0.02 & $2.4(1.1-5.2)$ \\
\hline & $\mathrm{p}$ for trend $\mathrm{d}^{\mathrm{d}}$ & 41 & $<0.001$ & $2.4(1.6-3.6)$ & 0.13 & $1.5(0.9-2.5)$ \\
\hline Marital status & Living with spouse & 35 & & 1.0 [Reference] & & 1.0 [Reference] \\
\hline
\end{tabular}




\begin{tabular}{|c|c|c|c|c|c|c|}
\hline \multirow{2}{*}{\multicolumn{2}{|c|}{ Categories of risk factors }} & \multirow[b]{2}{*}{$\begin{array}{c}\text { No. of } \\
\text { suicides }^{c}\end{array}$} & \multicolumn{2}{|c|}{ Unadjusted analysis } & \multicolumn{2}{|c|}{ Adjusted analysis $^{b}$} \\
\hline & & & p-value & HR $(95 \%$ CI $)$ & p-value & HR (95\% CI) \\
\hline \multirow{5}{*}{ Educational status } & Living without spouse & 6 & 0.09 & $2.1(0.9-5.0)$ & 0.76 & $1.2(0.5-2.8)$ \\
\hline & $\begin{array}{l}\text { Elementary school or } \\
\text { below }\end{array}$ & 16 & 0.002 & $3.6(1.6-8.2)$ & 0.04 & $2.4(1.0-5.6)$ \\
\hline & Middle school & 15 & 0.02 & $2.8(1.2-6.3)$ & 0.09 & $2.1(0.9-4.9)$ \\
\hline & High school or above & 10 & & 1.0 [Reference] & & 1.0 [Reference] \\
\hline & $p$ for trend ${ }^{d}$ & 41 & $<0.001$ & $0.6(0.4-0.8)$ & $\mathbf{0 . 0 3}$ & $0.7(0.5-1.0)$ \\
\hline \multirow{4}{*}{$\begin{array}{l}\text { Household income } \\
\text { per month } \\
\left(\text { Korean Won) }{ }^{\mathrm{e}}\right.\end{array}$} & Below 1,000,000 & 21 & $\mathbf{0 . 0 3}$ & $3.7(1.1-12.2)$ & 0.76 & $1.2(0.3-4.7)$ \\
\hline & $1,000,000-1,990,000$ & 16 & 0.29 & $2.0(0.6-6.8)$ & 0.79 & $1.2(0.3-4.4)$ \\
\hline & $2,000,000$ or more & 4 & & 1.0 [Reference] & & 1.0 [Reference] \\
\hline & $p$ for trend ${ }^{d}$ & 41 & 0.01 & $0.5(0.3-0.9)$ & 0.80 & $0.9(0.5-1.7)$ \\
\hline \multirow[t]{2}{*}{ Participant group } & Health exam group & 7 & 0.46 & $0.7(0.3-1.7)$ & 0.77 & $0.9(0.4-2.1)$ \\
\hline & Survey-only group & 34 & & 1.0 [Reference] & & 1.0 [Reference] \\
\hline
\end{tabular}

3 


\section{Table 4(on next page)}

Adjusted hazard ratios of suicides by depressive symptoms according to follow-up period $^{\mathrm{a}}$

BDI, Beck Depression Inventory; $\mathrm{Cl}$, confidence interval; HR, hazard ratio. a. Hazard ratios were calculated using a Cox proportional hazards model over multiple imputed data, after adjustment for age at enrollment, smoking status, drinking status, body mass index, selfrated health, marital status, educational status, household monthly income and participant group. b. Number of suicides may not match those of the other groups of depressive symptoms due to rounding of averages over multiple imputed data. c. Cut-off score based on quartiles and the last decile. $d$. Five categories of depressive symptoms were analyzed as ordinal variables. 
Table 4. Adjusted hazard ratios of suicides by depressive symptoms according to follow-up period ${ }^{\mathrm{a}}$

\begin{tabular}{|c|c|c|c|c|c|c|c|}
\hline \multirow{2}{*}{\multicolumn{2}{|c|}{ Categories of depressive symptoms (score) }} & \multicolumn{3}{|c|}{$\begin{array}{c}\text { From } 2001 \text { to } 2004 \\
n=10,238 \\
\end{array}$} & \multicolumn{3}{|c|}{$\begin{array}{c}\text { From } 2005 \text { to } 2008 \\
\qquad n=9,877\end{array}$} \\
\hline & & \multirow{2}{*}{$\begin{array}{c}\begin{array}{c}\text { No. of } \\
\text { suicides }^{b}\end{array} \\
16\end{array}$} & \multirow{2}{*}{$\begin{array}{r}\text { p-value } \\
0.02\end{array}$} & \multirow{2}{*}{$\begin{array}{c}\text { HR (95\% CI) } \\
1.3(1.1-1.8)\end{array}$} & \multirow{2}{*}{$\begin{array}{r}\begin{array}{c}\text { No. of } \\
\text { suicides }^{b}\end{array} \\
25\end{array}$} & \multirow{2}{*}{$\begin{array}{r}\text { p-value } \\
0.16\end{array}$} & \multirow{2}{*}{$\frac{\text { HR }(95 \% \text { CI) }}{1.1(1.0-1.4)}$} \\
\hline Total BDI score $(0-63)$ & Five-score increase & & & & & & \\
\hline \multirow[t]{2}{*}{ 2-group analysis ${ }^{\mathrm{c}}$} & No-to-moderate (0-30) & 4 & & 1.0 [Reference] & 10 & & 1.0 [Reference] \\
\hline & Severe (31-63) & 12 & 0.02 & $5.2(1.3-19.8)$ & 15 & 0.06 & $2.7(0.9-7.6)$ \\
\hline \multirow[t]{6}{*}{5 -group analysis ${ }^{\mathrm{c}}$} & No $(0-13)$ & 1 & & 1.0 [Reference] & 2 & & 1.0 [Reference] \\
\hline & Mild (14-21) & 3 & 0.70 & $1.6(0.1-17.6)$ & 3 & 0.87 & $1.2(0.2-8.4)$ \\
\hline & Moderate (22-30) & 1 & 0.99 & 0.0 & 4 & 0.80 & $1.3(0.2-9.2)$ \\
\hline & Severe (31-39) & 4 & 0.33 & $3.3(0.3-37.8)$ & 8 & 0.21 & $3.3(0.5-20.9)$ \\
\hline & Extreme (40-63) & 8 & 0.13 & $7.1(0.6-88.3)$ & 7 & 0.23 & $3.3(0.5-23.8)$ \\
\hline & Trend test ${ }^{\mathrm{d}}$ & 16 & 0.03 & $1.9(1.1-3.3)$ & 25 & 0.09 & $1.4(0.9-2.2)$ \\
\hline
\end{tabular}


Table 5 (on next page)

Diagnostic characteristics of Beck Depression Inventory by follow-up period in Korean middle-aged men

AUC, area under the receiver operating characteristics curve; $\mathrm{Cl}$, confidence interval. a. Cutoff score based on third quartile. b. $95 \% \mathrm{Cl}$ was calculated using Wilson score method. c. Proportion of true positives (suicides) correctly identified. d. Proportion of true negatives (non-suicides) correctly identified. e. A diagnostic test with an AUC value of 1.0 or 0.5 represents a perfect test or an uninformative test, respectively. 
Table 5. Diagnostic characteristics of Beck Depression Inventory by follow-up period in Korean middle-aged men

\begin{tabular}{|c|c|c|c|}
\hline \multirow[b]{2}{*}{ Follow-up period } & \multirow[b]{2}{*}{ Characteristics } & \multirow{2}{*}{$\begin{array}{c}\begin{array}{c}\text { Cut-off of } 31 \text { or } \\
\text { above }^{\mathrm{a}}\end{array} \\
\text { Rate }(95 \% \mathrm{CI})^{\mathrm{b}}\end{array}$} & \multirow{2}{*}{$\begin{array}{c}\text { Unbinned Total } \\
\text { Score } \\
\text { Rate }(95 \% \text { CI })^{b}\end{array}$} \\
\hline & & & \\
\hline \multirow[t]{3}{*}{ From 2001-2008 } & Sensitivity $^{\mathrm{c}}$ & $66(50-78)$ & \\
\hline & Specificity ${ }^{d}$ & $73(72-74)$ & \\
\hline & $\mathrm{AUC}^{\mathrm{e}}$ & $0.69(0.62-0.77)$ & $0.71(0.63-0.80)$ \\
\hline \multirow[t]{3}{*}{ From 2001-2004 } & Sensitivity $^{\mathrm{c}}$ & $75(50-90)$ & \\
\hline & Specificity $^{\mathrm{d}}$ & $73(72-74)$ & \\
\hline & $\mathrm{AUC}^{\mathrm{e}}$ & $0.74(0.63-0.85)$ & $0.75(0.61-0.90)$ \\
\hline \multirow[t]{3}{*}{ From 2005-2008 } & Sensitivity $^{\mathrm{c}}$ & $60(41-76)$ & \\
\hline & Specificity $^{\mathrm{d}}$ & $74(73-75)$ & \\
\hline & $\mathrm{AUC}^{\mathrm{e}}$ & $0.67(0.57-0.77)$ & $0.69(0.58-0.80)$ \\
\hline
\end{tabular}

3 